\title{
Denying and Preserving Self: Batswana Women's Experiences of Infertility
}

\author{
D intleK M ogobe
}

\begin{abstract}
ABST RACT
This qualitative study was conducted to understand and theoretically explain infertility from the perspective of 40 infertile women and four members of the traditional health care system. Symbolic interaction and feminism were combined to under-gird the study. Through ongoing data collection and analysis, a theoretical framework of denying and preserving self was constructed. Preserving self or self-preservation means developing personal measures aimed at preventing or reducing harm inflicted by others as a result of one's infertility. Contributory factors to denying of self include denial of status as a woman; denial of immortality; denial of experiences of pregnancy, labour and delivery; denial of economic and social security; and the belief that they are being chastised by $\mathrm{G}$ od and the forefathers. In addition, the women develop strategies to deal with such denials by looking for deeper meaning, working it out, giving in to feelings, getting more involved, getting away, and doing adoption. Implications of the study are discussed. (A fr J R eprod H ealth 2005; 9[2]: 26-37)
\end{abstract}

\section{RÉ SUMÉ}

$N$ ous avons mené cetteétude qualitative afin de comprendre et d'expliquer, de façon théorique, la stérilitéà travers la perspective de 40 femmes stériles et quatre membres du système de service de santétraditionnelle. N ous avons combiné l'interaction symbolique et le féminism dans l'étude. A travers la collection des données suivie et l'analyse, nous avons construit un cadre théorique del'abnégation et de l'instinct de conservation. L a préservation de soi ou l'instinct de conservation veut dire le développement des mesures personnelles qui visent la prévention ou la réduction du mal infligé par les autres à cause de la stérilité de soi. Les facteurs qui contribuent à l'abnégation comprennent la négation de sa situation de femme, la négation de l'immoralité, la négation des expériences de grossesse, du travail et de l'accouchement, la négation de la sécuritééconomique et sociale, et la croyance que c'est le bon $D$ ieu et les ancêtres qui les punissent. D e plus, les femmes conçoivent des stratégies pour contenir de telles abnégations tout en recherchant un sens plus profond, en recherchant la solution, en s'abandonnant aux sentiments, en s'impliquant davantage, en quittant et en adoptant un enfant. Les implications de l'étude ont été discutées. (R ev A fr SantéR eprod 2005; 9[2]: 26-37)

K EY W ORDS: Infertility, women, gender, B otswana

D epartment of $\mathrm{N}$ ursing $\mathrm{E}$ ducation, U niversity of Botswana, Private Bag 00702, G aborone, Botswana. T d: 00 267-3552362; E-mail: M ogobekd@ mopipi.ub.bw 


\section{Introduction}

Infertility is medically defined as the inability to conceive after a year or more of regular unprotected sexual intercourse. It affects both men and women of reproductive age in all parts of the world. E stimates on the prevalence of infertility are extremely variable in literature, and its occurrence varies from continent to continent as well as from country to country. Worldwide, it is estimated that $8-12 \%$ of couples (50-80 million people) experience some form of infertility during their reproductive years. ${ }^{1}$ In the $U S$, it is estimated that nearly 12 million people are infertile. ${ }^{2}$ In the B ritish population, at least as many as $16 \%$ of couples are believed to be affected by infertility. ${ }^{3}$ Infertility is believed to account for over $50 \%$ of cases seen in gynaecology clinics in the developing countries. In A frica, no reliable information is available about the prevalence of infertility, however, WHO estimates that as much as one third of all gynaecological and family planning resources are devoted to infertility and related problems. ${ }^{1}$ Several reports claim that gynaecologists spend two thirds of their consultation time on patients complaining of infertility., ${ }^{4,5}$

In a study conducted by M walali, Tharakan and Tharakan, infertility was reported to be the second most frequent cause of admissions to the gynaecology ward in Botswana. ${ }^{6}$ A ccording to the health statistics report of Botswana, outpatient attendance of patients having fertility problems between the ages of 15 and 45 years were 4400 , $45+$ years were 551 with a total of $4495(0.2 \%$ of all outpatients). ${ }^{7}$ These numbers do not include individuals and couples who were seen by private doctors, traditional healers and spiritual healers. Yet how this population of Batswana perceives and copes with their infertility is a topic that has been relatively neglected.

A review of literature on infertility in A frica has revealed that most studies such as those of Chatfield, Belsey and Frank focused on the incidence and causes of infertility. ${ }^{4,8,9} \mathrm{~A} n$ insignificant number of studies found that infer- tility "hurts", that it can be both traumatic and debilitating for women who, for personal and cultural reasons, view womanhood and motherhood as synonymous. While research investigating the causes and incidence of infertility abound, there was less literature about the experience of infertility and its psychosocial effects on the lives of the A frican women affected. Women researchers, women organisations, nurses and midwives had and still have done little, if anything, to give voice to the experiences of women with infertility. The reasons for their lack of interest are unclear. O ne of such is the fact that developing countries (B otswana included) have high fertility rates, hence, emphasis has been on the control of fertility while the problem of infertility is seldom discussed.

African women appear to bear the major burden of reproductive setbacks, including blamefor reproductive failure, personal grief and frustration, marital duress, social stigma and, in some cases, life-threatening interventions. ${ }^{10,11}$ Infertility is also related to many other important domains of social life, including kinship, inheritance, marriage divorce patterns, economic production, gender relations and notion of the body. ${ }^{10-12}$ Examining infertility also leads to the discovery of constructed meanings of motherhood, fatherhood and the children themselves, which is a critical area for further research particularly in Botswana where it has been relatively neglected. It is on the basis of this that the study was conducted.

\section{Purpose of the Study}

The study was conducted to understand and theoretically explain the phenomenon of infertility from the perspective of those who were experiencing it. The specific objectives were: to (1) describe the meaning of infertility from the perspective of women who were experiencing it; (2) identify and describe how women felt that their spouses, friends and other significant family members influence their meaning of infertility 
and; (3) delineate the processes and strategies used by women in dealing with infertility.

\section{M ethods}

Study Setting

The study was conducted in G aborone, capital city of the Republic of Botswana. It has a total population of 186,007 people, of which 94,184 are females. ${ }^{13}$

\section{C onceptual $F$ ramework}

The theoretical framework for the study was an integration of symbolic interactionism and the principles of feminism. Symbolic interactionism guided the theory, data collection and analysis, while principles of feminist research directed the ways in which the research was conducted, which informed the purpose of the research as well as the analysis.

Symbolic interactionism states that the unique characteristic of the human mind is the use of symbols to designate objects in the environment. With symbols one can rehearse possible actions, develop common meanings among parties in the interaction and put oneself in another's position. These purposes can facilitate adjustment and survival. Through interactions with others, one can crystallize self images into a stable though dynamic conception of oneself. Through accumulated interactions, one develops a self image as seen from the generalised other. ${ }^{14,15} M$ eanings are acquired during an individual's experience in the group, and these meanings lead to the development of self or an identity. Therefore, the underlying assumption in this study, derived from symbolic interactionism, is that identity of self is constructed and maintained with the social interaction that occurs between the individual and the environment. These ideas were clearly applicable to the situation of infertility in Botswana. Women who were experiencing infertility made meaning out of it, as they interacted with other persons in the environment. Women's experiences may be understood in terms of the meaning they attach to infertility. Women experiencing infertility interact with multiple people such as the mother, partner, friends, health care providers and many others. Therefore, the meaning of infertility arises during the process of interaction. They labelled themselves in a variety of ways as a result of what some members of the society made them believe.

Feminism is a broad term for a variety of conceptions of the relations between men and women in the society. ${ }^{16}$ It refers to a family of philosophies and strategies that are centred on women's experiences and interests. ${ }^{17}$ According to feminist theories, the researcher and participants should be equal partners in the research process, and women's experience is a legitimate source of knowledge. ${ }^{18,19}$ This framework led me to be aware of both the common experience and the differences in women's experiences. In order to allow for multiplicity and fostering of differences among participants, open-ended questions were used during the interview.

\section{Recruitment of Participants}

Recruitment of participants started after the research proposal was approved by the 0 ffice of the President, the M inistry of $\mathrm{H}$ ealth and relevant hospitals and clinics in Botswana. Recruitment of participants was done through the gynaecological clinic at Princess Marina H ospital (referral hospital) verbally and through the use of fliers. M ost of the participants (87.5\%) were receiving outpatient treatment at the infertility clinic. A small percentage $(12.5 \%)$ of women participants were recruited verbally.

\section{Samplesizeand D emographics}

D ata from interviews with 40 women aged 2144 years are presented in this paper. These include domestic workers, receptionists, general duty assistants, small business (running K iosk) owners and secondary school teachers. Type of 
D enying and Preserving Self: Batswana W omen's Experiences of Infertility

infertility was not considered before recruitment into the study, but if the woman perceived she had a problem, she was included in the sample.

Participants' educational level ranged from zero to 24 years of schooling with a mean of 8.2 years. O nly thirteen $(32.5 \%)$ of the forty participants were married. The rest (67.5\%) were single $(62.5 \%)$, separated $(2.5 \%)$ or engaged $(2.5 \%)$. Twenty five women $(62.5 \%)$ had no children at all (primary infertility), whilst fifteen $(37.5 \%)$ had one to three children each (secondary infertility).

\section{$D$ ata C ollection}

$D$ ata were collected through the use of qualitative interviews. The interviews were conducted for about six months (A pril to September 1997) and ranged in duration from about forty five minutes to one hour.

\section{Study Findings}

$D$ iscussion of the findings revolves around a theoretical framework of denying and preserving self. Preserving self means developing strategies to prevent or minimise harm inflicted by others as a result of infertility. The analysis sought to identify women's feelings about themselves as well as their constructed meaning of infertility that informed their self-care responses to the condition.

\section{D enying of Self}

The study findings revealed that women perceive infertility as denying of self to varying degrees within the larger social context of patriarchy. The contributory factors include denial of status as a woman; denial of economic and social security in old age; being chastised by God and the forefathers; denial of the experiences of pregnancy, labour and delivery; and denial of immortality. These denials are discussed.

\section{a. D enial of status as a woman}

Several women made reference to phrases such as "ga ona seriti" (one lacks dignity), "ga o mosadi wa sepe or "go nyenyafatsa bosadi jwa motho" (you are less of a woman), "ga o motho" (you are nobody). These were labelled as "denial of status as a woman". Participants believed infertility means that one is denied appropriate status in the society. A M otswana woman usually gains adult status as she gets to be called by the first child's name, $M$ ma Semangmang, meaning "mother of So and So". This practice, according to the women, shows respect as opposed to a woman with no children who continues to be called her first name. Therefore, failure to achieve motherhood brings with it lack of status and low self-esteem.

\section{b. D enial of economic and social security}

Batswana women perceive infertility as denial of social and economic security, specifically in old age. Within Botswana cultural contexts, children owe their parents a debt for bringing them into the world and rearing them. In order to pay this debt, children ought to pay respect to their parents partly through taking care of them in old age. $H$ aving children, therefore, is considered the best way of securing a reasonable socio-economic status in old age, and this security is definitely threatened by infertility. Two participants stated:

Theproblem is when you area grown up and have nobody to take care (emotionally, socially and economically) of you.

I am still young. I must have children, otherwise who will take care of me in old age?

\section{B eing chastised by $G$ od and great grandfathers}

Many women believed infertility means that one is being chastised for her omissions and commissions. This belief was evidenced by the constant use of the statement "petso ya M odimo" 
(G od's chastisement). Some women felt that they had sinned against $G$ od by not going to church earlier in their lives, or by becoming pregnant at an early age, having an abortion and not getting proper Setswana treatment for the abortion. This belief is driven by culture and religion that strongly emphasise that if a woman does any wrong, the ancestors or God will become angry with her, and as a result take away her fertility. Some women were uncertain of what wrong they might have done against either $\mathrm{G}$ od or their foref athers. 0 ne woman stated:

$G$ a ke itse gore ke diretse M odimo eng (I do not know in what ways I have wronged $G$ od).

Still another woman stated that several times she asked herself what she has done to her forefathers:

Tota badimo bame ke ba diretse eng se setona (what have I done to my forefathers that is so gross?)

\section{d. D enial of infertility through being named after}

In this study, two women stated that infertility simply means taking after somebody. 0 ne woman was named after her aunt who had no children at all. She believed that it was because of this identification with someone who had no children that she was experiencing infertility. A nother woman was given the name of a relative who had experienced infertility and she made reference to problems that included infertility on her part.

\section{e. D enial of immortality}

Childbearing gives an assurance of immortality, as one's name will be perpetuated through one's children, especially the sons. Consequently, the women believed that infertility means denial of immortality because there are no offspring. 0 ne woman said that everything about one would be forgotten if one dies childless.
There will be no remnants of her (children) on earth to show that she ever ex isted.

f. D enial of the experiences of pregnancy, labour and delivery

Women who were experiencing primary infertility felt that infertility denied them of the experiences of pregnancy, labour, delivery, breastfeeding and parenting. The women stated that they would like to experience pregnancy and labour pains so that they could also have something to talk about in the presence of other women. This denial is emotionally painful, according to them. The women reported that their emotional pain increases at social gatherings where they meet other women with children, especially as such gatherings always end up with discussions of experiences of either pregnancy or labour and delivery.

\section{g. B eing emotionally stressed}

In response to the question "W hat does infertility mean to you?", several women made reference to terms such as emotional pain, problems, worries and other similar words or phrases to convey the fact that they perceived infertility as emotionally painful. These responses were grouped together and termed emotional pain or stress. Reasons for the emotional pain included insults from in-laws and the presumably fertile population, not being called "So and So's mother, having noticed that women of the same age or even younger ones have children, and lack of dignity.

0 ther women have to endure significant emotional abuse by partners especially around their menstrual periods. Women reported how, because of disappointments, partners use abusive language on them, beat them and accuse them of secretly taking contraceptive tablets or sleeping with many men. 0 ther men become so angry that they leave the home and stay away for days. 0 thers just sit at home without talking to their spouses. 
Strategies for Preserving Self

Women developed various strategies to overcome or deal with the problem of these denials. Those strategies were discovered by asking the question: "Since you realised that you had an infertility problem what have you done in order to cope?" Participants reported the use of a variety of coping strategies to manage their denial of self. These strategies were for self-preservation. Selfpreservation means developing strategies aimed at either protecting oneself from getting emotionally hurt or harmed by others or reducing the harm inflicted by others. The strategies include looking for deeper meaning, giving in to feelings, working it out, compromising, getting more involved, getting away, or doing adoption.

\section{a. L ook ing for deeper meaning}

The first strategy used for preserving self was looking for deeper meaning. Sub-categories as trust in God through prayer, spiritual reawakening, questioning and looking for hidden meaning were put together to form the category looking for deeper meaning. The women sought existential meaning. $M$ any of them found comfort by looking for hidden reasons for their infertility. $M$ any believed that it was $G$ od's will. O newoman stated:

Ke k gona go ipolelela gore ke kabelo ya M odimo, fa M odimo o sa mpha bana ga go na sepe se ke ka se dirang (meaning that it was $G$ od's will that she had no children, so let it be, as there was nothing that she could do).

The women in this study reported that they commonly ask themselves the questions: "why me", "why at this point" and "why in this way". This was initially coded as questioning. U sually the answer that they got from the traditional healers had something to do with ancestral beliefs. 0 ther women got their answer through their Bible readings.

D uring the process of infertility treatments and failures many women felt helpless without
God and this led to the insight that allows for a new understanding of self. The women realised their grounding in God's powers, that without God's will they would not have children. This process of a woman's direct experience of her grounding in G od's powers was labelled "spiritual re-awakening." The women believed more strongly in G od, hence, they attended church more frequently than when they had not realised that they were infertile.

\section{b. G iving in to feelings}

The second strategy for preserving self was "giving in to feelings". This is defined as crying, neglecting tasks, and having suicidal ideas. M any of the women gave in to their intense feelings of sadness, frustration and depression at not being able to conceive. The women stated that they cry many times because of their infertility. Crying served as a form of relief to some women, because after they gave in to their emotions and cried, they felt better equipped to deal with their unfulfilled goal. For others, "giving in" involved neglecting tasks such as having to close their small businesses or even neglecting their personal hygiene. 0 ther women reported that they became so depressed that they entertained ideas of committing suicide. Some women reported attempted suicide. M any women tended to cry more or have suicidal ideas during menses because of disappointment that conception had definitely not occurred. Some women said they cried because of anger on the part of their partner. O ne woman said:

\section{A that time (menses time) I was so hurt and scared of my partner that I took tablets and a glass of water with the intention of swallowing them all. I sat there, stared at the tablets, but then ran out of courage and just started crying.}

\section{Workingit out}

A nother commonly used strategy was "working it out". Working it out means engaging in 
discussions with husband, traditional healers, relatives and other women with experience of infertility in order to find solutions to the problem. It also included subcategories of negotiating and mutual sharing. N egotiating was done with husband and members of the traditional health care system. Women negotiated with their partners/ spouses, relatives and friends for more and more money as they moved from one doctor to the other to seek help. M oney was needed for transport, accommodation and treatments. In the case of traditional healers, where the fees were higher, women had to negotiate to pay in instalments. U nfortunately, medical insurance does not cover the use of traditional healers, so the women had to pay the bills in full. In the event that all interventions failed they still had to negotiate with partners/spouses and family members for adoption. Legal adoption of a child from a non-relative was almost always unacceptable to the husband and family members, and in some cases created family conflict.

The women were also "working it out" through sharing their problems with their husband, friends or other women who were experiencing the same problem. They were able to share their problem under the conditions of a supportive environment. Some of the women admitted sharing the burden with their husband. O ne woman stated:

I have a partner, I share this problem, I fel very much supported, and since I have his support, I come to fed much better, because like I was saying earlier, when he is here, I sleep comfortably.

"Sharing the burden" with other infertile women was rarely mentioned by the women. O nly two out of forty women mentioned that they shared the problem and information with other women who were experiencing the same problem. The two women said they shared their problems and searched for more information from other women experiencing infertility when they met at infertility clinics. N one of the women, however, mentioned looking for more information from literature.

Although some women felt that sharing strengthened their relationships, unfortunately a larger percentage ended up with marital discord or broken relationships. 0 ne woman stated:

Several men left me because I can't have children and it is a painful thing to go through.

\section{d. Compromising accommodating}

Women utilised this strategy by allowing or even encouraging their husbands to have children with other women. These other women could be relatives or any other woman. Compromise also included accepting and taking care of their husband's children from other women. This was the ultimate coping strategy used by some women. I term it "ultimate" because it seemed to be used by women out of desperation. They use this strategy when they feel that they can no longer have children or when their husband is threatening to leave for another woman.

\section{e. G etting moreinvolved}

"G etting more involved" was another strategy used by women. This is defined as seeking active treatment from providers in the health care system and getting involved in infertility treatments. All women reported the use of this strategy to a large extent. This strategy consisted of actual involvement in infertility treatments. Therapeutic modalities involved the use of drugs, herbs, fumes, purgatives, sea water, epsom salts, body massage, etc. These therapeutic modalities were provided by self-proclaimed physiotherapists, traditional healers, faith healers and members of the modern health care system.

\section{f. G ettingaway}

This is defined as emotionally distancing oneself from the struggle of denying and preserving self. Thestrategy involves combining the subcategories 
of shifting focus and taking a break. Four (10\%) of the women said that they kept themselves busy with their career-related activities or got involved in community service, which kept them busy to the extent that at times they momentarily forgot about their infertility problem. This kind of distraction was termed shifting focus.

Some women got to a point that they felt they had exhausted almost all interventions without success. In such a situation they felt that they needed a break from infertility treatments.

\section{g. D oingadoption}

The seventh strategy used by women was "doing adoption". This was a rare strategy and women thought of doing adoption only after all attempts at conceiving a biological child failed. When asked about adoption, few women were aware of the legal adoption option. The few women who understood the process of legal adoption were faced with resistance from their husbands/ partners and/ or family members. Resorting to such option was considered a mistake.

All women were aware of the traditional form of adoption (go abelwa/ tsalelwa ngwana) though they were still against it. Women experiencing infertility did not favour the customary form of adoption for several reasons. First, they stated that the identity of the biological parents is never kept secret. As a result, as the child grows, people are likely to tell the child that mosadi yo ga se mmago (this woman is not your real mother). As the women explained, the child may then eventually return to his/ her biological parents. Second, there is a problem of parental intervention, especially if the biological parents believe that their child is not treated well by the adoptive parents. The biological parents may eventually seek custody of their child.

As a result of the problems associated with adoption, only three women in the study had considered adoption. The first woman was in the process of legally adopting a child. The second one failed because of lack of support from her husband and family members and the third woman was thinking of in vitro fertilization in the future.

\section{Discussion}

The constructed meaning of denial of status as a woman in the society is derived from the way girls are socialised in the Tswana culture. In the Tswana culture, a girl has her earliest relationships with her grandmother, mother, sister, aunt and other older women. Throughout childhood, women are socialised that on reaching adulthood they should get married and start a family. ${ }^{20} \mathrm{As}$ she grows up, the woman takes up the images of the women around her and consciously and unconsciously internalises what it means to be a woman in Botswana.

In Botswana, womanhood is generally considered to be synonymous with motherhood. Motherhood is rather a mandate and not an option. As Schapera noted, children symbolise several things in Tswana society; among them it makes the father a man and the mother a woman. ${ }^{21}$ Schapera stated that with the birth of the first child, couples acquire a new dignity. The man has proved his manhood as he has a child who would perpetuate his family name and memory. The woman has fulfilled her supreme destiny. ${ }^{21}$ A ccording to Schapera, the birth of the first child also enhances the status of couples, as reflected in the change of names. They (couples) now become generally known by the child's name - mother of So and So, or father of So and So. Therefore, the significant purpose of sexual act remains a reproductive one.

B atswana women perceive infertility as denial of the experience of pregnancy, labour and delivery. In their day-to-day lives, women socialise with other women, friends and relatives. It is during these periods that issues such as labour pains and raising of children arise. Unfortunately, those women who have never experienced labour pains then feel out of place, as they have nothing to talk about in relation to such issues.

Batswana women perceive infertility as a denial of social and economic security especially

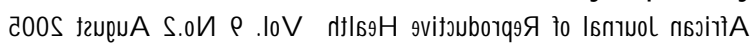


in old age. Throughout their childbearing years women bear children and take care of them at a young age. In old age, women depend on children for both economic and social security, particularly in a developing country like Botswana where government has few social welfare programmes. As clearly stated by Matebesi, children are expected to take care of their parents in old age, since there are no nursing homes in Botswana. ${ }^{11}$ Thus, in Botswana it is mainly the children and not the government who provide social and economic security to their aged parents. The government is less burdened when children assume responsibility for the aged. Therefore, having children is considered the best way of securing a reasonable socio-economic status in old age, and this security is certainly threatened by infertility.

Women made reference to denial of immortality. Botswana is a patriarchal society and most women take their husband's name when they get married. Consequently, it is the husband's name that is then passed to the children. Children, especially sons (girls get married and change name), ensure one's immortality because one's name will be perpetuated by future generations. Infertility, or specifically the lack of a son, threatens immortality.

As a result of the numerous denials that they experienced, women felt emotionally stressed, they felt like their personhood was disintegrating or falling apart. Consequently, they developed strategies to reduce such stress. Such strategies sought self-preservation. As mentioned earlier, preserving self means developing strategies to prevent or minimise emotional harm inflicted by other people in the woman's environment. Strategies could be described as what is commonly known in infertility literature as coping strategies. Coping strategies refer to the specific efforts, both behavioural and psychological, that women employ to reduce or minimise harm resulting from the stressful infertility.

Women reported the use of both emotionfocused and problem-solving strategies in order

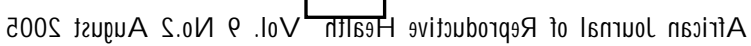

to cope with infertility. Emotion-focused strategies (such as looking for deeper meaning, giving in to feelings and getting away) included efforts to regulate the emotional consequences of infertility. Problem-solving strategies, such as working it out or getting more involved, aimed at finding solutions to the cause of infertility. Folkman and Lazarus indicated that people use both types of strategies to combat stressful events. ${ }^{22}$

Some of the strategies reported by women have roots in the old/ traditional Tswana custom. For instance, compromising/ accommodating as a strategy has roots in the old/ traditional Tswana custom. Schapera explained that the husband of an infertile woman has a right to ask his wife's family or she herself would request them to provide him with another woman with whom to bear children. ${ }^{20,21}$ Any children she (surrogate mother) bears him are then regarded as the children of the first wife. A lthough through such a process, the first wife suffers some form of misery and humiliation, she does not complain sincethis is considered better than being sent away (divorced).

Accommodation or compromising, as a strategy, was perhaps useful in the olden days, before the era of HIV/AIDS. N owadays, because of the risk of being infected with sexually transmitted diseases including HIV / AIDS, the strategy should be discouraged. As explained earlier, accommodating/ compromising involves allowing a spouse to have a child with another woman. The practice of multiple partnerships and unsafe sex exposes couples to the risk of contacting sexually transmitted diseases including HIV/ AID S. This is particularly scary in a country like Botswana with an HIV rate of $37.4 \%{ }^{23}$

It is worth noting that "doing adoption" was only thought of after all attempts at conceiving a biological child had failed. A ttempt at using this strategy was only employed by three women. Adoption is not common because of certain beliefs and practices. Some Batswana believe that moral character is hereditary, and that an adopted child can be assumed to have the biological 
parents' character. For instance, if the parents of an adopted child are thieves, the child would also be a thief. The B atswana believe that even if such a child is put in a different environment, she/ he will eventually become like his/ her biological parents. Although children who are known (by adoptive parents) are considered to be better adoptive candidates, the practice was viewed as problematic by thewomen experiencing infertility because of periodic interference from the biological parents. Interference from biological parents is common in situations where they feel that the child is not properly cared for. E ventually, according to the women, such a child may return to his/ her biological parents.

The other reason for the lack of use of such strategy was that very few women were aware of the process of legally adopting a child. Reasons for the lack of information regarding legal adoption are unclear to the researcher. Perhaps not much effort has been put into educating couples about legal adoption. As a result of the existence of such beliefs, practices, lack of information on legal adoption and resistance from the family, neither traditional nor legal adoption is acceptable to women experiencing infertility.

Strategies used to preserve self (reduce or prevent harm from others as a result of infertility) do not include two obvious strategies. First, women did not attempt to deflect any insults or name calling by blaming or naming their spouses as the reproductive "failure". Tswana culture does not allow women to publicly fault their husbands. Consequently, women become the target of any name-calling and other forms of abuse for infertility.

Second, there is no mention of the use of a support group. Use of a support group is not mentioned because such a group does not exist for infertility. Although there are longstanding women's groups in the country aimed at advancing women's issues, none of the groups ever attempted to encourage a support group for couples experiencing infertility. The struggle of women with infertility remains a private issue.

\section{I mplications of the Study}

First and foremost the study has implications for the usual definition of infertility, nursing education, practice and research, as well as wider implications on policies in Botswana. The results of this study revealed that infertility is not restricted only to biology, but it also affects a total sphere of a person's life. For instance, thestudy revealed that infertility affects marriage, social and economic security, and women's identity. The results could mean that as observed at different periods by other authors, the usual definition is restrictive ${ }^{25}$ and should vary from culture to culture. ${ }^{26}$

The study findings have implications for nursing and midwifery curricula. M ore needs to be done to integrate infertility into the Botswana nursing and midwifery curricula. The study has revealed many of the psychosocial and cultural issues related to infertility. These cultural and psychosocial issues should be integrated into all aspects of nursing or midwifery curricula. Since women experiencing infertility need counselling, nurses and midwives need to acquire more skills in counselling. Counselling skills are useful to enhance and improve communication, learn to listen effectively, and to facilitate a conducive environment for movement towards acceptance of infertility.

The study revealed that women have various cultural and religious beliefs about the causes of infertility. It should lead to the development and implementation of appropriate therapeutics and comprehensive programmes for couples experiencing infertility. Infertility research in Botswana has not addressed who should be targeted (among all members of the institutions experiencing infertility) and how intervention should be approached. While different approaches to infertility are possible, I recommend a comprehensiveprogramme. I mportant components of a comprehensive programme include prevention of infertility through health education and improvement of the environment, awareness raising of the whole society, more research studies 
in the area, and modification of health policies. This type of comprehensive programme is based on an ecological model for health promotion and aims at modification of the individual beliefs and practices as well as the environments within which infertility is experienced.

The study revealed that infertility is an individual as well as a family matter. A larger study that includes men/ husbands and some members of the extended families of women experiencing infertility is necessary. A comparative study of the meaning of infertility among presumably fertile and infertile women would be useful.

Policymakers could use the results of this study as they develop policies related to sexual and reproductive health.

\section{Conclusions}

Infertility, as a worldwide problem, needs more attention especially in pronatalist countries like Botswana where it is a burden for a woman. The study has revealed that infertility is an important phenomenon that affects all of a person's life. It is my hope that the medical and nursing community and the public at large will become aware of its implication on the definition that is usually restricted to biological functioning. Attempt to define infertility in the developed world may not be appropriate because of the way it is viewed in Botswana.

As the study has revealed that infertility is a serious matter in Botswana, members of the health team and the government at large should address it seriously based on some of the study findings. Provision of care should reinforce the need to involve couples rather than women alone. A t least the initial assessment of infertility should include husband and wife/ spouse. As women did not mention the use of support groups, they should be encouraged with the assistance of a midwife or any relevant health worker to form such support groups within the country. The positive aspect of support groups is that members share common concerns. Women with infertility would help each other understand the experience and get help from others who have gone through similar experiences. Infertility support groups would provide an accepting environment where there is empathy. It is within such groups that women could express their feelings and know that they are understood. As most women in this study were not fully informed about legal adoption available in the country, it is important that the adoption system be examined in order to make it more accessible to couples experiencing infertility.

\section{Acknowledgements}

Support for this study was provided by the U niversity of Botswana with funds from K ellogg Foundation, although the views expressed in this article do not reflect those of the U niversity or K ellogg Foundation.

\section{References}

1. World $\mathrm{H}$ ealth $\mathrm{O}$ rganization. Infertility: A Tabulation of $A$ vailable $D$ ata on Prevalence of Primary and Secondary Infertility. G eneva: WH O Program on M aternal and Child $\mathrm{H}$ ealth, 1991.

2. K rishnan V. Attitude toward surrogate motherhood in Canada. $\mathrm{H}$ ealth $\mathrm{C}$ are for $\mathrm{W}$ omen International 1994; 15: 333-357.

3. Raval et al. The impact of infertility on emotions and the marital and sexual relationship. I R eprod Infant Psychol 1987; 5(4): 221-234.

4. Chatfield WR, et al. Theinvestigation and management of infertility in E ast A frica: a prospective study of 200 cases. E A fr M ed J 1970; 212-216.

5. M ati JKG. Infertility in A frica: magnitude, major causes and approaches to management. I 0 bstet $G$ yneacol E C ent A fr 1986; 5(65): 65-69.

6. M walali, Tharakan and Tharakan. Fertility differentials for antenatal clients and infertility clients in Princess $M$ arina H ospital. Unpublished research study. G aborone, Botswana, 1990.

7. Central Statistics $\mathrm{O}$ ffice. $\mathrm{H}$ ealth Statistics. $\mathrm{G}$ aborone Printing and Publishing, 1995. 
8. Belsey MA. The epidemiology of infertility: a review with particular reference to sub-Saharan Africa. B ull W orld H ealth 0 rg 1976; 54: 319-340.

9. Frank 0. Infertility in sub-Saharan A frica: estimates and implications. Pop D ev R ev 1983; 9(1): 137- 144.

10. Inhorn $M C$ and Buss KA. Ethnography, epidemiology and infertility in E gypt. Soc Sci M ed 1994; 39(5): 671-686.

11. Matebesi $L$. What arethe cultural issues associated with infertility of women in Botswana? Unpublished B. E d. N ursing dissertation, $\mathrm{G}$ aborone, Botswana, 1994.

12. $H$ irsch $A M$ and $H$ irsch $S M$. The effect of infertility on marriage and self-concept. J 0 bstet $G$ ynecol N eonatal N urs 1998; 18(1): 13-20.

13. Central Statistics. Botswana $\mathrm{H}$ ousing and Population C ensus. G aborone G overnment P rinter, 2001.

14. Turner JH. The Structure of Sociological Theory. 5th edition. B elmont: Wadsworth, 1991.

15. Blumer $\mathrm{H}$. Symbolic Interactionism: Perspective and $M$ thod. Berkely: University of California Press, 1969.

16. M annathoko $C$. Feminist theories and the study of gender issues in Southern Africa. In: $G$ ender in Southern A frica: Conceptual and Theoretical I ssues. H arare: Sapes Trust, 1992.

17. Leslie M. Stiwanism: feminism in an African context. In: R ecreating 0 urselves: A frican W omen and
Critical Transformation. Trenton: A frica World Press, Inc, 1994.

18. Campbell J and Bunting S. Voices and paradigms: perspectives on critical and feminist theory in nursing. A dv N urs Sa 1991; 13(3): 3-15.

19. Wuest]. Feminist grounded theory: an exploration of the congruency and tensions between two traditions in knowledge discovery. $\mathrm{Q}$ ualitat $\mathrm{H}$ ealth R es 1995; 5(1): 125- 137.

20. Schaperal. Some K gatla theories of procreation. In: Suggs $D$ and M iracle AW. Culture and $H$ uman Sexuality: A Reader. California: Brooks/ ole Publishing Company, 1929-1939.

21. Schaperal. A $H$ andbook of $T$ swana $L$ aw and $C$ ustom. London: $O$ xford U niversity Press, 1955.

22. Folkman $S$ and Lazurus RS. Stress, A ppraisal and Coping. N ew York: Springer Publishing Company, 1984.

23. M inistry of State President, The $N$ ational AIDS Coordinating A gency. B otswana Second $G$ eneration H IV / A ID S Survéllance G aborone: G overnment Printer, 2003.

24. A gunloye K . Infertility: a socio-cultural definition. N ig N urse 1978; 10(3): 27-29.

25. Louw DJ. Pastoral care to the infertilecouple. Paper presented at the A nnual Conference for M arriage and F amily Therapy, Washington D C, 1990. 